\title{
Archival gamma ray logs standardization by nondestructive core measurements of the low-radioactivity rocks
}

\author{
Rafał Skupio $^{1}$ (i) $\cdot$ Benedykt Kubik ${ }^{1} \cdot$ Krzysztof Wolański $^{2}$
}

Received: 3 May 2019 / Accepted: 8 August 2019 / Published online: 21 August 2019

(C) The Author(s) 2019

\begin{abstract}
The present study analyzes spectral gamma ray data of low-radioactivity rock cores from Rotliegend Basin. The main goal of this research was standardization of archival gamma ray logs measured in counts per minute to American Petroleum Institute units. Selected core intervals, log data, and additional crushed samples covered three different boreholes: J-1, L-7, and K-2 from Zielona Góra Basin, localized in western Poland, where J-1 was a reference borehole. Core measurements were performed on the sandstone and conglomerate formations by Gamma Logger GT spectrometer, which uses two scintillation detectors containing bismuth germanate crystals. In the cores, real concentrations of potassium, uranium, and thorium were acquired what enabled to calculate total content of radioactive elements and total uninfluenced by uranium. Delivered new total GR_GLGT curve from cores allowed accurate standardization of archival GR curves from L-7 and K-2 boreholes. Presented results showed a very good correlation between logs, core data, and laboratory analyses. These data allow precise shale volume reinterpretation.
\end{abstract}

Keywords Rotliegend $\cdot$ Core logging $\cdot$ Well logging $\cdot$ Gamma radiation $\cdot$ Spectrometry

\section{Introduction}

The gamma ray measurements (GR) are used as a foundation in quantifying shale volume, what allows for lithological interpretation and zone correlation from well to well (DíazCuriel et al. 2019). Gamma ray emission from the rocks is related with the presence of naturally radioactive clays and ions associated with them (Ellis and Singer 2007). Spectral gamma ray measurements enable to obtain data, containing individual mass concentration of potassium, uranium, and thorium. Signal from the sum of K, U, and Th counting rates allows the calculation of total GR, converted to American Petroleum Institute (API) units (Ellis and Singer

The paper was presented at the CAGG 2019 Conference "Challenges in Applied Geology and Geophysics" organized at the AGH University of Science and Technology, Krakow, Poland, 10-13 September 2019.

Rafał Skupio

skupio@inig.pl

1 Well Logging Department, Oil and Gas Institute - National Research Institute, Lubicz 25 A, 31-503 Cracow, Poland

2 Polish Oil and Gas Company, Boh. Westerplatte 15, 65-034 Zielona Gora, Poland
2007). Data acquired by gamma ray logging tools (wireline) are not affected by background noise, because all radiation comes from rocks nearby detector. Unfortunately, drilling mud, flushed zones, caves, and casing of the well can have a negative influence for logs quality (Rider 2000). Spectrometric data from clean drilling core are not influenced by borehole effects, but surrounding radiation of the environment makes a high background noise. Background radiation comes inter alia from cosmic radiation, building materials, the detector, and the measurement method itself (Blum et al. 1997; Lindstorm 2017). For rocks of low radioactivity, type of shielding, assay time, and place of measurements are crucial. The wireline gamma ray, after wellbore influence corrections, should give the same results as core logging and laboratory measurements, despite different environmental conditions and geometrical settings.

Until the 1990s, natural gamma ray logs in Poland were performed with the use of Russian tools. These types of devices were not calibrated to any standard and measured only total gamma ray in counts per minute (CPM) units. Recorded data were influenced by detector types, their size, and efficiency (Ellis and Singer 2007). Radiation levels acquired in CPM were not comparable in specific strata, because in every run, tool amplification was changed to 
have better count rates of the detector. Archival logs saved in CPM could be standardized in petrophysical software based on the minimum and maximum count rates and interpreter intuition, but final results still may differ. Bolesta and Gałąza (2014) proposed conversion algorithm wrote in Python script, which enabled recounting CPM into API standard units. Nowadays, all the gamma ray logging tools employed in Poland are standardized in API units, what allows for the comparison total intensity of natural radiation in specific rock types.

This research was focused on the accurate archival log standardization to API units by the core measurements. Nondestructive analysis, such as spectral gamma ray, provided the possibility of performing continuous core logging with laboratory precision (Skupio and Barberes 2017). Proper application of GR logs standardization in archival boreholes localized in particular region is crucial for reinterpretation process. It gets a new approach to the mature gas fields. The Polish Oil and Gas Company has access to the gamma ray logs recorded in CPM units and cores drilled before 1990. In core repositories, there are well-maintained archival cores, drilled from hundreds of boreholes. It can be used to get new spectrometric data in core interval and change quality of archival logs by precise standardization. It should be noted that measurements of short parts of the cores from one lithology cannot replace well logging of spectral gamma ray in the whole borehole.

\section{Geographical and geological framework}

Three boreholes chosen for standardization process are localized in Zielona Góra Basin (western Poland) which is sub-basin of Polish Rotliegend Basin. Both geological units belong to Southern Permian Basin, a big geological structure that covers England, Netherlands, North Sea, Denmark, and Poland (Zagórska et al. 2016). This region is well recognized by a large number of old exploration and production wellbores, but has not enough log data to draw new conclusions. Increasing efficiency of exploration work in this area requires new basic log data as spectral gamma ray, standardized in API units. Oil and gas fields discovered in the Rotliegend of Southern Permian Basin have been explored for more than 50 years (Karnkowski 1994). There were three predominant depositional systems: fluvial, aeolian, and playa lake. Climate and tectonics were major factors of sedimentary development in described basin (Kiersnowski 1997). Kiersnowski and Buniak (2006) were analyzing wireline logs, calibrated by core data and regional correlation distinguished nine successive Upper Rotliegend depositional cycles. These cycles are characterized by conspicuous heterogeneity and lateral extent (Kiersnowski and Buniak 2006).
Localization of the three boreholes (J-1, L-7, and K-2) is indicated in Fig. 1. The distance between K-2 and L-7 boreholes is about $130 \mathrm{~km}$, and J-1 is about $50 \mathrm{~km}$ away from K-2. Cores that were measured in this study were built from fine-grained sandstones and conglomerates from Permian Rotliegend series. Approximate depth of chosen core intervals reaches: for J-1 from 2365 to $2716 \mathrm{~m}$, for L-7 from 1788 to $1824 \mathrm{~m}$, and for K-2 from 2558 to $3348 \mathrm{~m}$. Borehole L-7 which is southeastern from J-1 is characterized by shallow deposition of Rotliegendes and thickness only about $80 \mathrm{~m}$. K-2 is localized northwest from J-1, where investigated strata are deposited from $2550 \mathrm{~m}$ and have more than $800 \mathrm{~m}$ of thickness.

\section{Methods and techniques}

Standardization of old gamma ray logs by new spectrometric measurements on the cores was carried out with the use of new methodology. For this project, archival well logs dataset containing gamma ray curves in CPM units (K-2 and L-7) and newer dataset from J-1 containing spectrometric curves were used. Borehole $\mathrm{J}-1$ was a reference, because it contained wireline spectral gamma ray: $\mathrm{K}(\%), \mathrm{U}(\mathrm{ppm})$, Th (ppm), GR (API), and GRS (API). These logs were used to make a comparison with core and laboratory data, for new measurement and calculation methodology verification.

New core and laboratory data were performed in Well Logging Department of the Oil and Gas Institute-National Research Institute and in the Central Core Repository. Gamma ray core measurements were carried out with the use of Gamma Logger GT-GLGT apparatus, adapted for the analysis of low content of radioactive elements in the core structure. For borehole J-1, standard gamma loggerGL (Skupio and Dohnalik 2015), also was used to compare quality of data between two logging devices. GL apparatus was set for $5 \mathrm{~min}$ of measurements and step for $10 \mathrm{~cm}$. It measured also empty parts of the core, and during data processing, these intervals were erased. For the verification of core logging data and methodology accuracy, laboratory analysis of radioactive elements content with the use of MAZAR spectrometer was made (Kowalska et al. 2010). Time of laboratory measurements was set for $6 \mathrm{~h}$ per sample. Furthermore, mineralogical analysis was carried out using XRD method (Rietveld 1969; Środoń et al. 2001), for checking the accuracy of shale volume interpretation.

Vasiliev et al. (2011) developed a high-efficiency and low-background system with eight 4 " $\mathrm{NaI}(\mathrm{Tl})$ detectors and thick lead shielding. It measured simultaneously eight points in the core marine sediments sections with $20-\mathrm{cm}$ step. In this research, spectral gamma ray data from low radioactive cores were collected by gamma logger GLGT device (Fig. 2). GLGT is a new high-efficiency 


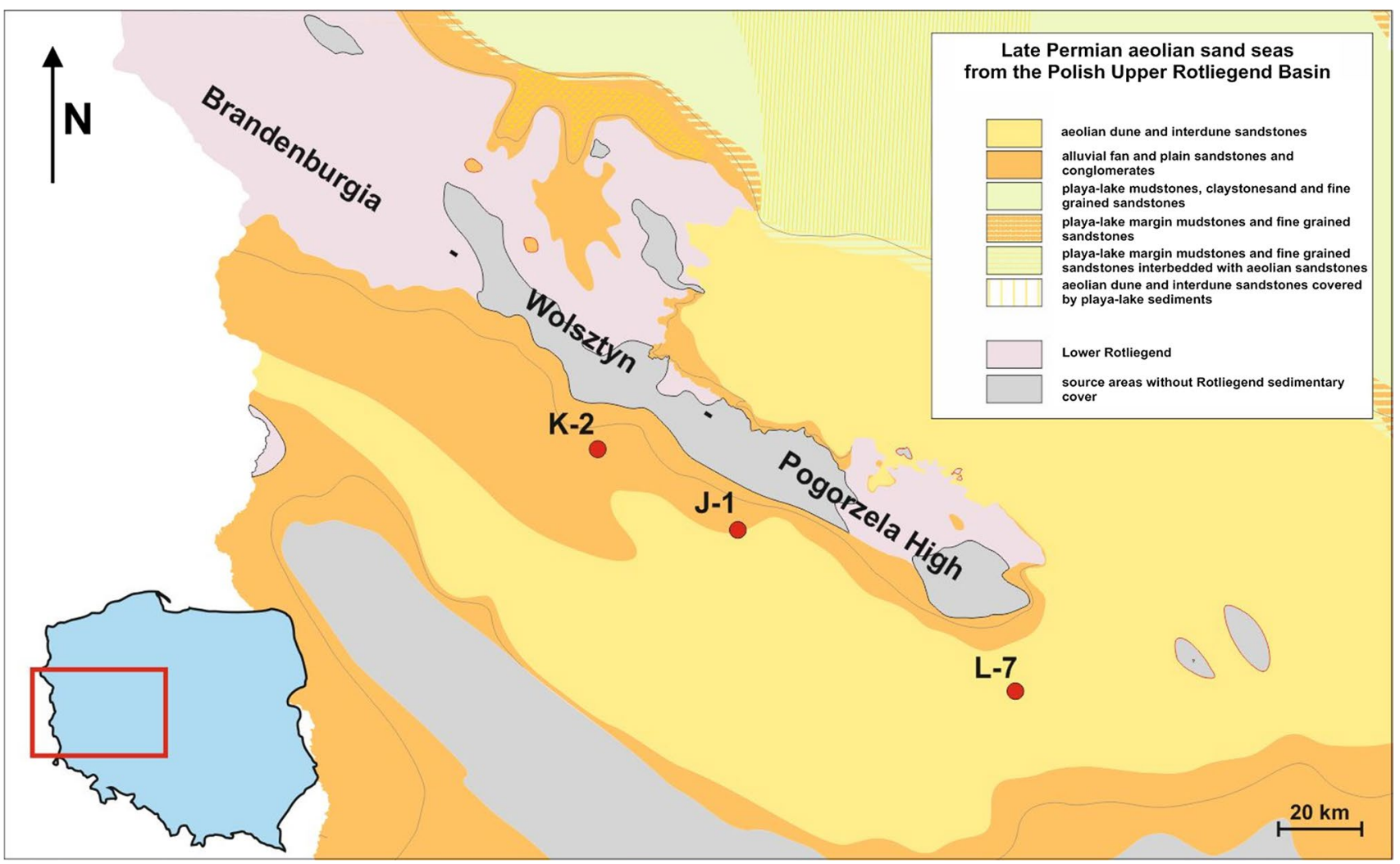

Fig. 1 Approximate locations of the three boreholes in the examined district are indicated with red dots. The map presents a part of the Polish Rotliegend Basin (A. Buniak, the map from PGNiG archives)

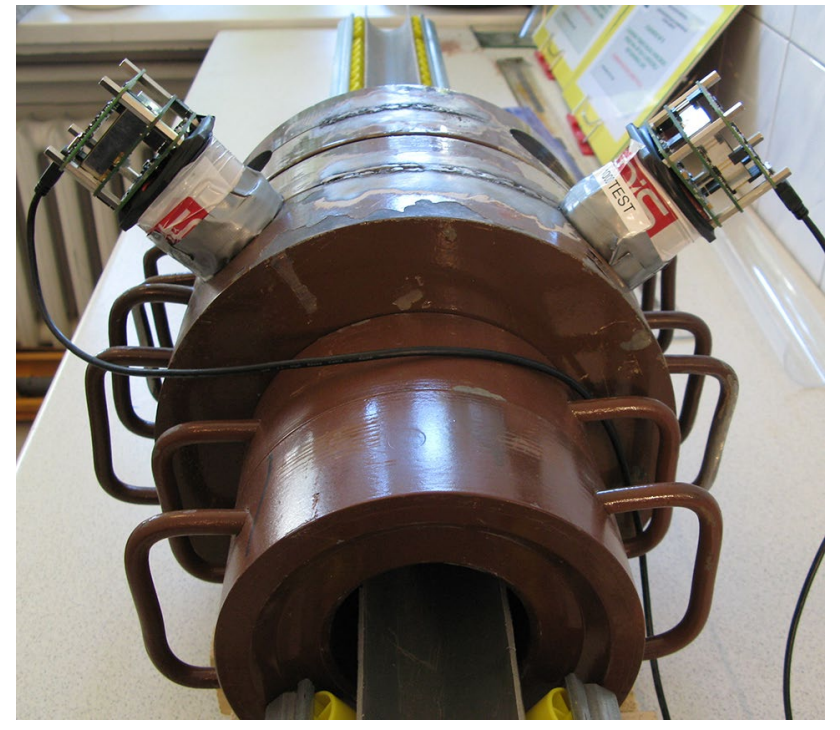

Fig. 2 Gamma logger spectrometer GLGT adapted to low-radioactive core measurements. Two independent BGO detectors were placed at a $90^{\circ}$ in lead tunnel shielding and low-background system developed by Well Logging Department with Georadis s.r.o cooperation. It measures one point on the core with two detectors in one run. Archival sandstone cores have many voids and destroyed parts; the system enables direct measurements on the chosen spot of the well-preserved material. GLGT spectrometer was built on the basis of double 2-in. BGO scintillation detectors $\left(\mathrm{Bi}_{4} \mathrm{Ge}_{3} \mathrm{O}_{12}\right.$-bismuth germanate) and lead shielding from MAZAR spectrometer. Two high-efficiency BGO detectors allows for a reduction in the measurement time (Hendriks et al. 2001; Van der Graaf et al. 2007) and are on average $10 \%$ more efficient than $\mathrm{NaI}(\mathrm{Tl})$ detectors of the same size (Knoll 2000), but their spectrum resolution is poorer compared with $\mathrm{NaI}(\mathrm{Tl})$ crystals (Bakkum et al. 1984; L'Annunziata 2012). Thickness of the shielding wall reaches $10 \mathrm{~cm}$, total length of shielding is about $40 \mathrm{~cm}$, and detectors are placed in the middle; it allows to measure cores with diameter up to $7 \mathrm{~cm}$. Lead segments could be separated, what is desirable during device transportation. For easier core handle, roller conveyor with core holder was mounted. Detectors and software to operate were developed by Georadis s.r.o. (Skupio et al. 2019). To obtain real concentration, $\mathrm{K}, \mathrm{U}$, and Th set of standards, with the shape of cylinder, was applied. Length of the 

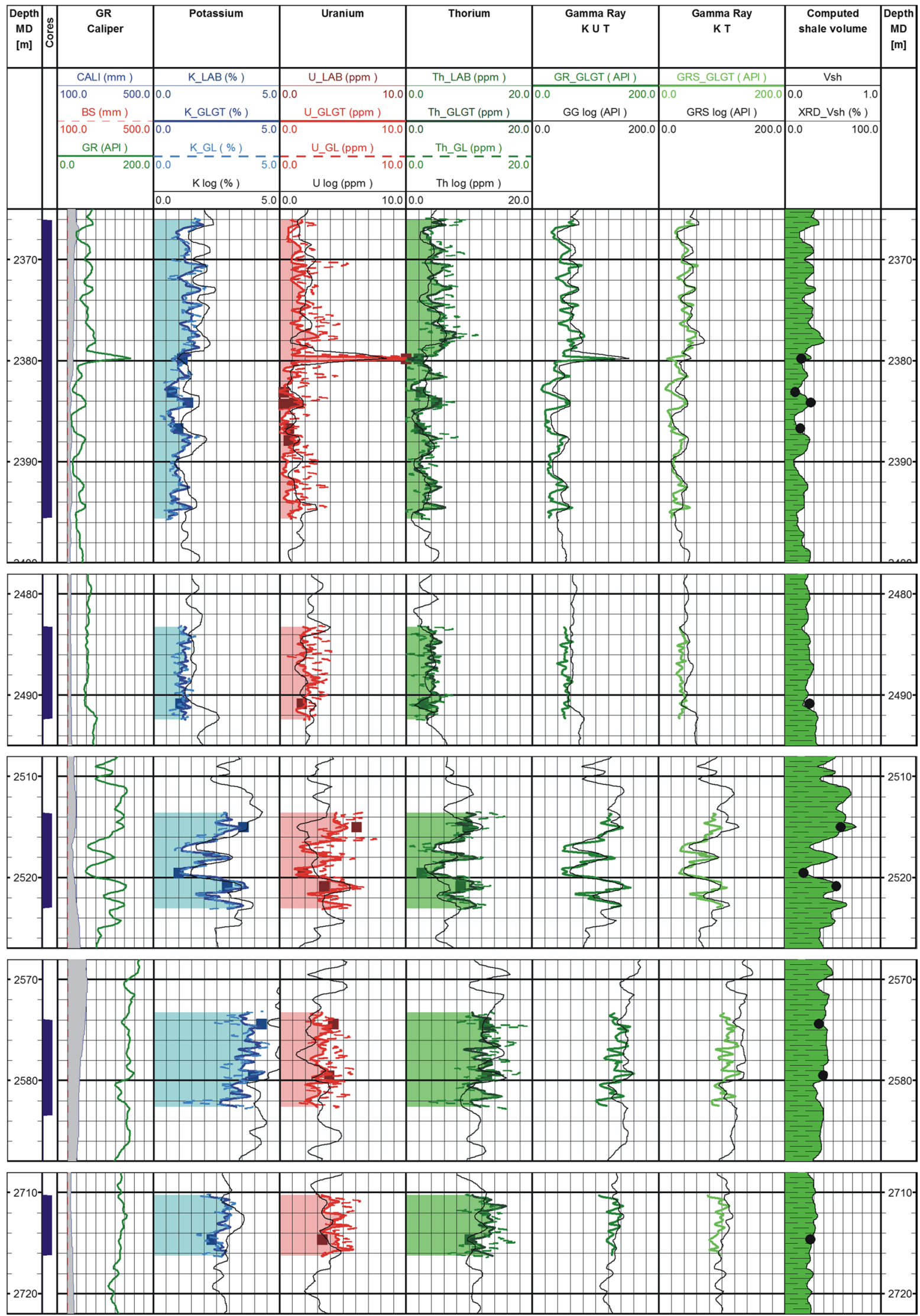
4Fig. 3 Set of natural gamma ray results with shale volume interpretation from J-1 borehole. Spectrometric data from GL, GLGT, and laboratory presented on the background of well logs. Laboratory data are showed as points in the tracks

cylinders was about $35 \mathrm{~cm}$, and diameter was $7 \mathrm{~cm}$. Time for every standard measurement was set for $10 \mathrm{~min}$. It is important to note that the device calibration must be run on site for recording noise of local background. Time of core measurements was set for $5 \mathrm{~min}$, and step was variable and dependent on the core physical condition. Two detectors were working at the same time, what enabled to sum two independent spectra and have an equivalent of 10-min measurement. GLGT measures energy range up to $3 \mathrm{MeV}$ emitted by the core. Spectral analysis utilizes energy windows set for characteristic energy peaks emitted by radioactive elements like potassium $\left({ }^{40} \mathrm{~K}\right)-1.46 \mathrm{MeV}$, uranium $\left({ }^{238} \mathrm{U}\right)-1.76 \mathrm{MeV}$ and thorium $\left({ }^{232} \mathrm{Th}\right)-$ $2.62 \mathrm{MeV}$ (Blum et al. 1997).

Spectra from measurements were acquired by testing software, designed by Georadis s.r.o. It enabled to collect and save the spectra from two detectors at the same time. The real concentrations of elements are computed in external software, which requires spectra from standards, spectra from core measurements, and settings of ROI range (region of interest-range of energy windows on the spectrum). Tested software uses the least-square method to compute the most probable contents of $\mathrm{K}, \mathrm{U}$, and Th. It compares shape of spectra from core measurements in ROI, to the shape of standard spectra at that same range (Bartosek 1977).

In this work, standardization of the archival boreholes was made on the basis of total gamma ray curves, which were calculated from real concentration of $\mathrm{K}, \mathrm{U}$, and $\mathrm{Th}$ in the cores. GLGT and other spectrometers for core or laboratory measurements are not standardized to API units. Core logging data were calculated by formulas: GR $(\mathrm{API})=4 \mathrm{Th}+8 \mathrm{U}+16 \mathrm{~K}$ and GRS$[\mathrm{API}]=4 \mathrm{Th}+16 \mathrm{~K}$ (Ellis and Singer 2007), to get total gamma ray activity and total uninfluenced by uranium in API units. Standardization of archival curves was made on the basis of the measured core, curve shape, and regression formula. For results visualization and K, U and Th conversion to total in API units, ProGeo 6.6 software was used. Before calculation process, core intervals were matched to the logs depth.

For quality checking of proposed methodology, $77 \mathrm{~m}$ of the core from J-1 was measured by GL and GLGT. Additionally, after core logging, 11 crushed samples for laboratory analyses were taken. For standardization process, $30 \mathrm{~m}$ of L-7 and $137 \mathrm{~m}$ of K-2 from archival cores were measured only by GLGT spectrometer. In L-7 borehole, 10 samples were collected for laboratory analyses. Diameter of the cores was about $6.4 \mathrm{~cm}$, and samples taken for laboratory tests had $150-160 \mathrm{~g}$.

\section{Results and discussion}

This research was focused on the three boreholes, containing archival well logging data and new core and laboratory measurements. Core intervals chosen for analysis came from Rotliegend Basin represented by sandstones and conglomerates formations. Some parts of these intervals have very low content of radioactive elements. Sandstones cores, in most cases, were preserved in good physical condition, and some segments were destroyed by sampling or not appropriate storage. Cores from J-1 were measured in the laboratory facility, because additional tests and methodology preparation were necessary for new spectrometer setup. L-7 and K-2 data were acquired in the core repository. Boxes for core storage were in bad physical condition what made it impossible to transport it to the laboratory. Archival well logging database from L-7 and K-2 boreholes had only GR curve in CPM units, and it was used for standardization to API units.

Presented depths in boreholes are artificial, due to lack of permission for depth presentation from data owner. Imaginary depth values were presented for the result description.

\section{$\mathrm{J}-1$ results}

Rotliegend sediments in J-1 borehole occur from 2380 to $2735 \mathrm{~m}$. Five available core intervals that were measured came from depths: I-2365-2395 m, II-2483-2493 m, III-2514-2524 m, IV-2574-2583 m, V-2710-2716 m. Samples from interval I were composed by fine-grained sandstones and from interval II by conglomerates. Other intervals from $2493 \mathrm{~m}$ were composed by both lithologies. Lower radiation strata in this case correspond to conglomerates and higher to sandstones. Full dataset of results from J-1 borehole was presented in Fig. 3.

Cores from J-1 were measured by GL and GLGT spectrometers. Curves from GL were presented using dash line in the tracks. To have better curve matching, arithmetic mean filter averaging five adjacent points was applied. Despite filtering, some intervals showed negative results for uranium and thorium, and all the data had a bigger background influence. Data from GLGT were presented using lines with shadings. These curves had lower background influence and better accuracy, filtering was not applied, and all the results were positive. GLGT curves were more precisely matched to well logs than GL curves. These comparisons shows that both spectrometers works correct but GLGT is more accurate and less time consuming. Laboratory data confirmed spectrometric data correctness. For conversion from K, U, and Th to GR/GRS 
in API units and results evaluation, GLGT measurements were used. Total GR_GLGT curve and GG from logs in API standard are almost the same, as well as curve uninfluenced by uranium GRS_GLGT and GRS $\log$ (API).

Core data from J-1, measured by GLGT were divided into two sections, with low and high radioactivity. First one includes I and II intervals, where following mean spectrometric core data were acquired: $\mathrm{K}=1.14 \%, \mathrm{U}=1.15 \mathrm{ppm}$, $\mathrm{Th}=3.80 \mathrm{ppm}, \mathrm{GR}=43$ API and GRS $=33$ API. Second, deeper section includes intervals from III to $\mathrm{V}$, resulted: $\mathrm{K}=2.86 \%, \mathrm{U}=2.91 \mathrm{ppm}, \mathrm{Th}=10.28 \mathrm{ppm}, \mathrm{GR}=110 \mathrm{API}$ and GRS $=87$ API. Core depth distribution enables to determine spectrometric data in various levels of radiation in sandstone and conglomerate formations. Uranium and thorium content in core and well logs were at the same level. Potassium content in the core and laboratory measurements was a little lesser than from wireline, probably because of the potassium mud applied in the wellbore. It caused a little lesser final GR_GLGT curve comparing to GG log from wireline. Before logs evaluation, core and laboratory data were matched to well log depth.

Shale volume interpretation was made on the basis of GRS log curve with the use of linear formula. XRD results were used for accurate shale level setting. During interpretation of Rotliegend deposits, much higher radiation levels were noticed from $2493 \mathrm{~m}$. This interval had a larger accumulation of potassium and thorium, but shale volume data from XRD analysis did not show much higher content of illitic materials. This problem with greater $\mathrm{K}$ and
Th content in sandstones was examined by Kowalska et al. (2010). Potassium is related with common feldspars and thorium with monazite occurred in investigated strata. During reinterpretation, for depths from $2493 \mathrm{~m}$, another reference level was set, according to mineralogical data.

Correlation of the well logs and core logs made by GLGT spectrometer is shown in Fig. 4a, and in Fig. 4b, correlation of the gamma ray laboratory measurements with shale content from XRD is presented.

The gamma ray data from well logs and from core measurements presented a strong correlation (Fig. 4a). Coefficient of determination for GR total is: $R^{2}=0.94$, whereas for GRS (total uninfluenced by uranium), it is: $R^{2}=0.93$. Scatter plot with GR and GRS from laboratory measurements with shale volume from XRD data is presented in Fig. 4b. Dataset was divided into two classes: Red dots indicates strata with higher radioactivity which corresponds to potassium feldspars and monazite content. Shale volume and gamma ray in Rotliegend deposits have much higher determination coefficient $R^{2}=0.97$ for data uninfluenced by uranium (GRS), comparing to total GR data $R^{2}=0.38$ (blue dots). Anomalous $\mathrm{K}$ and Th contents must be analyzed on different levels, what was considered during shale volume interpretation.

Tests conducted on the J-1 borehole confirms correctness of new methodology which could be applied for archival boreholes. All the measurement methods used in J-1 was consistent. Better accuracy and a lower background influence in GLGT apparatus encourage usage of this apparatus in case of sandstone and conglomerate formations. GL
Fig. 4 Correlation graphs of logs with core measurements for GR and GRS (a) and correlation graphs of XRD shale volume with GR and GRS from MAZAR spectrometer (b)
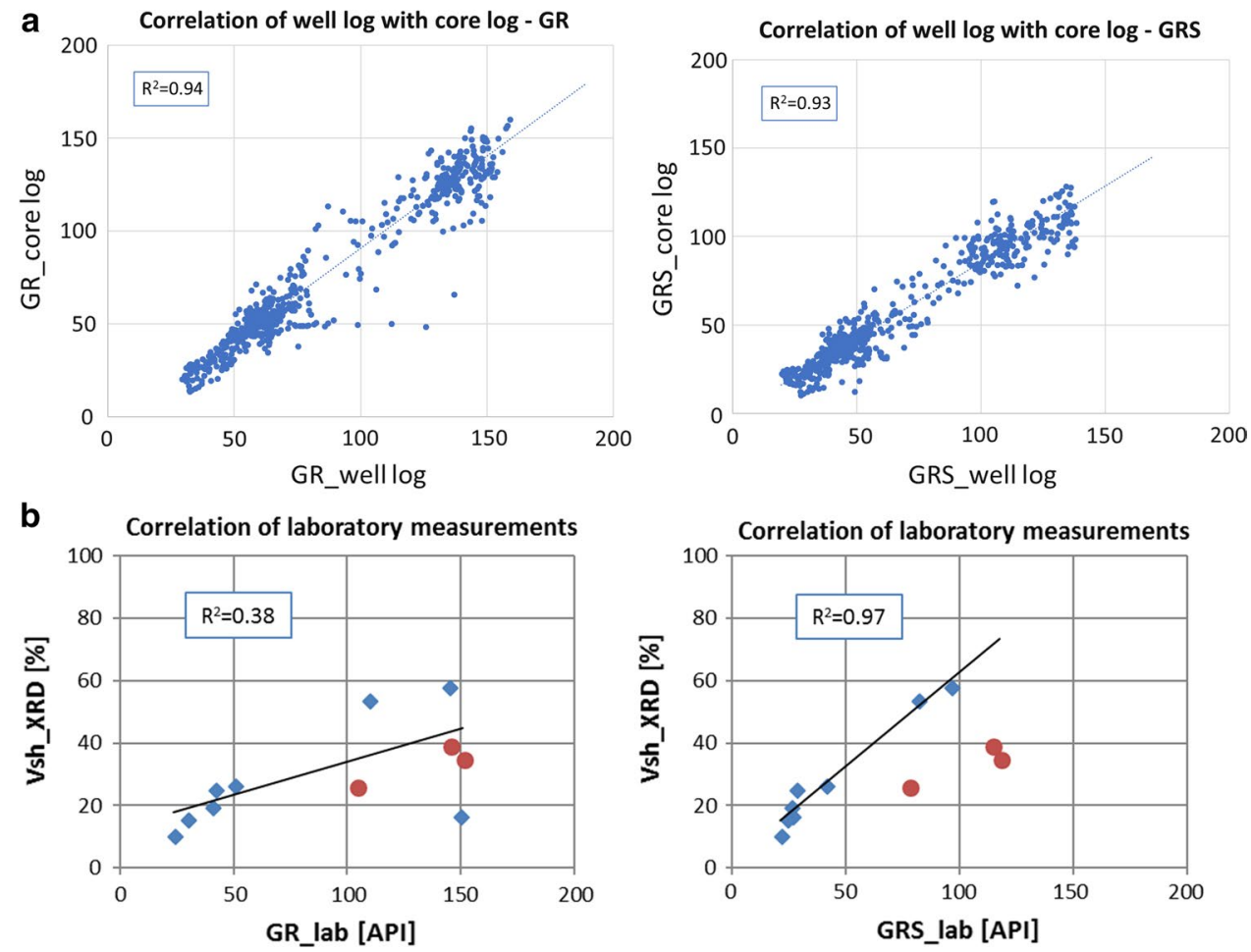
spectrometer can be applied as well, but data are not complete in low radioactive intervals and have bigger statistical errors.

\section{L-7 results}

Borehole L-7 is the first one with application of the core standardization methodology. For this process, $30 \mathrm{~m}$ of the core was measured. GLGT spectrometer was used in the core repository, where local calibration was done. Device settings were that same, as in J-1 case. Ten samples were taken for laboratory analyses, to check whether new calibration and interpretation results are correct. Fine-grained sandstone formations start from depth $1790 \mathrm{~m}$, below high uranium peak, and reach up to $1865 \mathrm{~m}$. Mean results for core measurements (without higher uranium peak) are: $\mathrm{K}=0.84 \%, \mathrm{U}=0.86 \mathrm{ppm}, \mathrm{Th}=2.42 \mathrm{ppm}, \mathrm{GR}=30 \mathrm{API}$ and GRS $=23$ API. Graphical results of measurements, result of standardization, and shale volume interpretation are presented in Fig. 5.

For L-7 borehole, new spectrometric data in the core interval were received. In this region, sandstone formations occur at lower depth comparing to other two boreholes and have very low $\mathrm{K}$, $\mathrm{U}$, and Th content. Laboratory measurements of uranium could not be determined because of MAZAR limitations. Uranium results were below the limit of detection $(<1.5 \mathrm{ppm})$. After the measurement process, GR_GLGT and GRS_GLGT curves in API were estimated in the core interval. These newly standardized curve parts enabled to use simple regression formula for GR (CPM) log to obtain new precise GR curve (GR cal), in API standard units. In L-7 borehole, strata with higher potassium and thorium content that could correspond to feldspars and monazite were not found. Additional XRD analyses helped with exact shale volume interpretation which was calculated with linear formula on the basis of GR cal curve.

Shale volume interpreted on the basis of GR, standardized in API units and laboratory data of mineralogical interpretation (XRD), presented a strong correlation in borehole L-7: $R^{2}=0.8$ (Fig. 6). It confirms that standardization of archival GR curve and interpretation of shale volume were correct and can be compared with other boreholes.

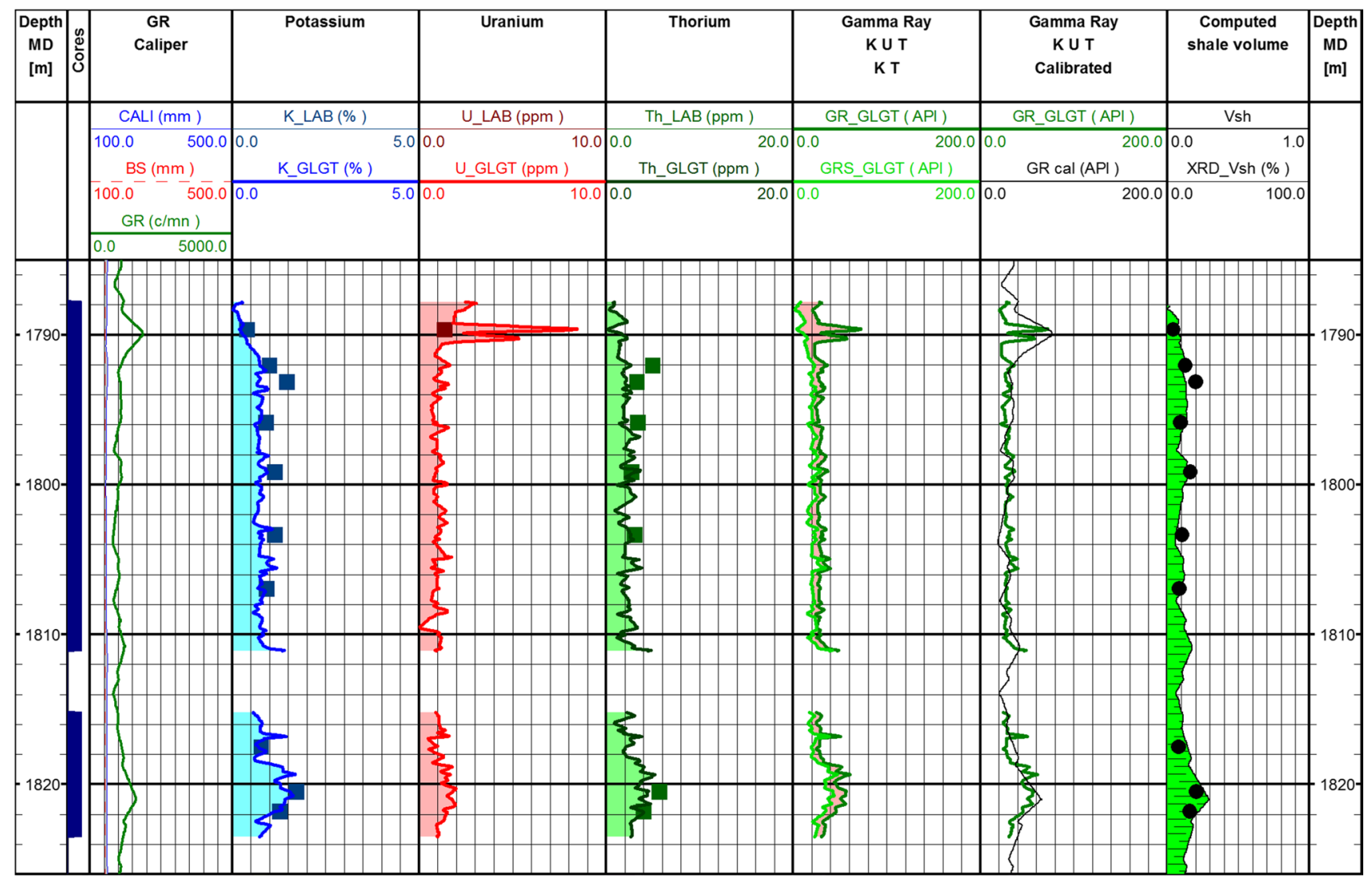

Fig. 5 Set of natural gamma ray results with shale volume interpretation from L-7 borehole. Spectrometric data from GLGT and laboratory, presented with the GR before and after standardization (GR cal). Laboratory data are showed as points in the tracks 


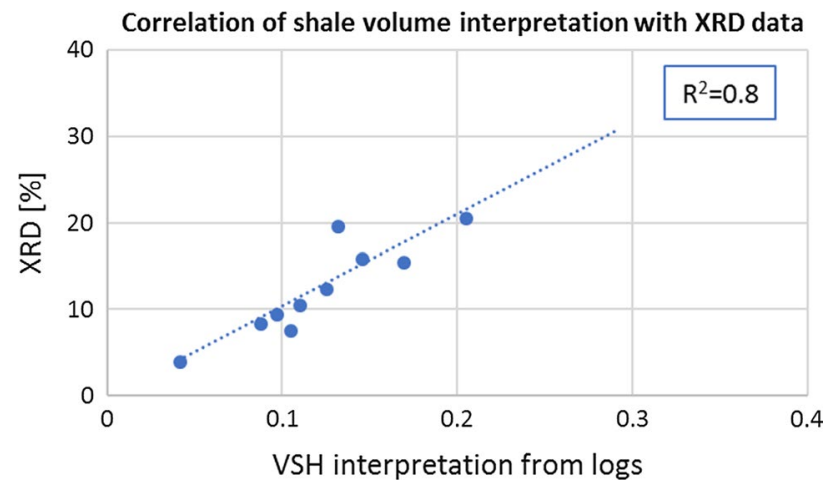

Fig. 6 Correlation graph of XRD data and shale volume interpretation made in L-7 borehole

\section{$\mathrm{K}-2$ results}

Rotliegend deposits in K-2 borehole have more than $800 \mathrm{~m}$ of thickness. Archival gamma ray log was standardized in entire interval. Reference curves were measured by GLGT spectrometer in five sections, including $135 \mathrm{~m}$ of the core. Calibration and measurements were done in the core repository with that same device settings as in J-1 and L-7 case. Fine-grained sandstones and conglomerates from Rotliegend Basin start from $2567 \mathrm{~m}$, below high uranium peak and reach to $3348 \mathrm{~m}$. Mean spectrometric results for core measurements are given in Table 1.

First interval mostly composed by fine-grained sandstones, and few conglomerate layers have medium values of total gamma ray. Intervals from II to IV have higher content of radioactive elements especially section III where anomalous uranium content was noticed. Interval V was measured as $20-\mathrm{cm}$ core section (one point), and it corresponds to the lowest gamma ray levels in this borehole. Archival gamma ray well $\log$ in CPM was standardized to API units basing on the core measurements in various sections. Shale volume interpretation was made on the GR cal curve standardized in API units. Laboratory XRD analyses were not conducted in $\mathrm{K}-2$, and for this reason, shale volume level was set by extrapolation from shale levels from J-1 and L-7 borehole. In K-2 borehole, higher vertical resolution for GLGT measurements comparing to well log has been noticed. Graphical results of measurements, result of standardization, and shale volume interpretation are presented in Fig. 7.

Comparing radiation levels of sandstones and conglomerates in three examined boreholes, it can be noticed that Rotliegend deposits have different radiation levels. L-7, which is located in the SE of investigated area and deposits are on smaller depth, has the lowest mean radioactivity, total $\mathrm{GR}=30$ API. J-1 which is localized between L-7 and K-2 has interesting radiation levels division, upper part has low content of radioactive elements GR $=43 \mathrm{API}$, whereas lower part has anomalous content of $\mathrm{K}$ and $\mathrm{Th}$ what causes higher $\mathrm{GR}=110 \mathrm{API}$, which does not correspond to shale volume. K-2 is localized in NW part of investigated area, and Rotliegend deposits are much deeper and thicker than in case of J-1 and L-7. The upper part of K-2 has medium radiation level GR $=63$ API, but lower part (one measured point) has lower GR $=46$ API. The middle part containing II, III, and IV intervals has higher radioactive elements concentrations $\mathrm{GR}=113$ API. Mineralogical analysis was not done in K-2 borehole, but there is a chance that higher radiation levels correspond to $\mathrm{K}$ and $\mathrm{Th}$ as in $\mathrm{J}-1$ case.

\section{Conclusions}

GLGT apparatus enabled to obtain high-quality spectral data $(\mathrm{K}, \mathrm{U}, \mathrm{Th})$ from the cores of low content of radioactive elements. GLGT had better accuracy than GL, and GLGT curves needed no filtration to correspond to logs. The improvement in data quality was visible especially for uranium and thorium. The core data showed better vertical resolution comparing to wireline. The tests conducted on the J-1 borehole showed that methods and calibration standards are correct as well as the calculation method for API standard is acceptable. On the basis of gamma ray core measurements, it was possible to standardize archival GR curve recorded in CPM to 'GR cal' in API units, with high accuracy. The standardization was made for boreholes L-7 and K-2. Calculated new GR curves enabled precise shale volume interpretation in whole interval of sandstones and conglomerates from Rotliegend Basin. For more precise interpretation and
Table 1 Results of mean values in determined core sections from K-2 borehole

\begin{tabular}{|c|c|c|c|c|c|c|c|}
\hline Interval & $\begin{array}{l}\text { Depth } \\
\text { (m) }\end{array}$ & range & $\mathrm{K}(\%)$ mean & $\mathrm{U}(\mathrm{ppm})$ mean & Th (ppm) mean & GR (API) mean & $\begin{array}{l}\text { GRS } \\
\text { (API) } \\
\text { mean }\end{array}$ \\
\hline I & 2560 & 2650 & 1.49 & 2.33 & 2.17 & 63 & 44 \\
\hline II & 2680 & 2690 & 2.60 & 3.61 & 8.21 & 103 & 74 \\
\hline III & 2740 & 2750 & 2.61 & 7.60 & 9.38 & 140 & 79 \\
\hline IV & 3290 & 3330 & 2.00 & 3.61 & 9.10 & 97 & 68 \\
\hline V & 3349 & 3349.1 & 0.85 & 2.85 & 2.47 & 46 & 23 \\
\hline
\end{tabular}



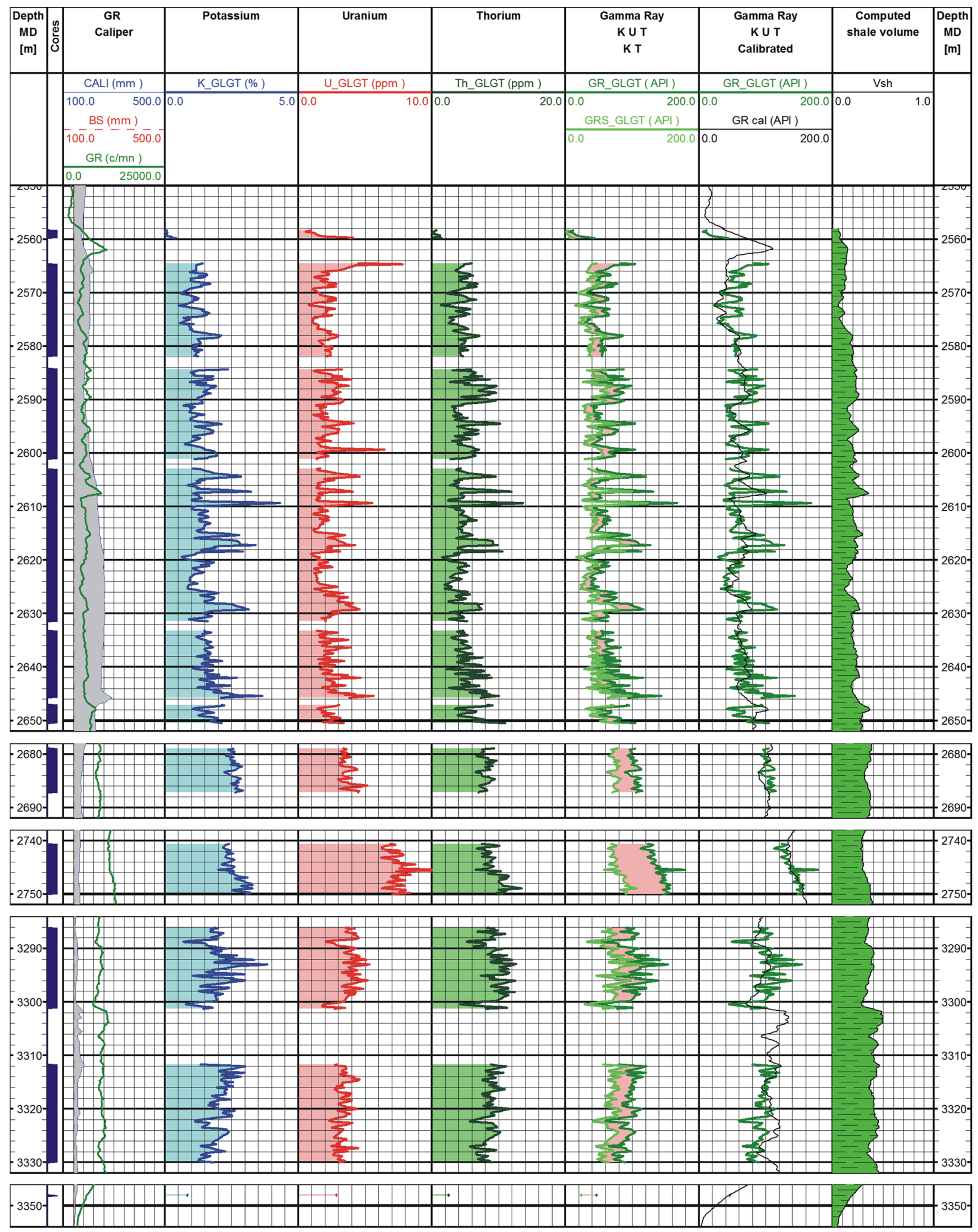

Fig. 7 Set of natural gamma ray results with shale volume interpretation from K-2 borehole. Spectrometric data from GLGT presented with the GR before and after standardization (GR cal) 
higher vertical resolution, core data could be used to calculate shale volume with the use of GRS curve (only in the core intervals). Standardized gamma ray data from the three boreholes could be compared with other gamma ray logs in API standard, made in Zielona Góra Basin.

Acknowledgements The authors extend grateful thanks to The Polish Oil and Gas Company (PGNiG) for well logging data sharing and permission to publish this article. This research was supported by PGNiG during '172/385/SW/2017' project realization.

Open Access This article is distributed under the terms of the Creative Commons Attribution 4.0 International License (http://creativecommons.org/licenses/by/4.0/), which permits unrestricted use, distribution, and reproduction in any medium, provided you give appropriate credit to the original author(s) and the source, provide a link to the Creative Commons license, and indicate if changes were made.

\section{References}

Bakkum EA, Van Engelen CPM, Kamermans R, Teeling TA, Timmerman LJM (1984) The response of BGO scintillation detectors to light charged particles. Nucl Instrum Methods Phys Res 225:330-334

Bartosek J (1977) Citliva metoda stanoveni obsahu prirozene radioaktivnich prvku v horninach. Kandidatska disertacni prace. Geofizika Brno

Blum P, Rabaute A, Gaudon P, Allan JF (1997) Analysis of natural gamma-ray spectra obtained from sediment cores with the shipboard scintillation detector of the ocean drilling program: example from leg 1561. In: Shipley TH, Ogawa Y, Blum P, Bahr JM (eds) Proceedings of the Ocean drilling program, Scientific Results, p 156

Bolesta F, Gałązka A (2014) Profilowanie gamma-przeliczanie jednostek. Nafta-Gaz 8:493-501

Díaz-Curiel J, Miguel MJ, Biosca B, Medina R (2019) Environmental correction of gamma ray logs by geometrical/empirical factors. $\mathrm{J}$ Pet Sci Eng 173:462-468

Ellis DV, Singer JM (2007) Well logging for earth scientists, 2nd edn. Springer, Berlin

Hendriks PHGM, Limburg J, de Meijer RJ (2001) Full-spectrum analysis of natural gamma-ray spectra. J Environ Radioact 53:365-380
Karnkowski PH (1994) Rotliegend lithostratigraphy in the central part of the Polish Permian Basin. Geol Q 38:27-42

Kiersnowski H (1997) Depositional development of the Polish Upper Rotliegend Basin and evolution of its sediment source areas. Geol Q 41:433-456

Kiersnowski H, Buniak A (2006) Evolution of the Rotliegend Basin of northwest Poland. Geol Q 50:119-138

Knoll GF (2000) Radiation detection and measurement, 3rd edn. Wiley, New York

Kowalska S, Lewandowska A, Buniak A (2010) Reasons of the anomalous indications of the gamma ray logs for the Lower Permian rocks from the Wolsztyn High area. Nafta-Gaz 6:425-440

L'Annunziata MF (2012) Handbook of radioactivity analysis, 3rd edn. Elsevier Inc., New York

Lindstorm RM (2017) A second-generation low-background gammaray spectrometer. Appl Radiat Isot 126:191-193

Rider M (2000) The geological interpretation of well logs, 2nd edn. Whittles Publishing, Dunbeath

Rietveld HM (1969) A profile refinement method for nuclear and magnetic structures. J Appl Crystallogr 2:65-71

Skupio R, Barberes GA (2017) Spectrometric gamma radiation of shale cores applied to sweet spot discrimination in Eastern Pomerania, Poland. Acta Geophys 65:1219-1227

Skupio R, Dohnalik M (2015) Improvement spectrometric gamma measurements on shale cores with the use of the BGO scintillation detector. Nafta-Gaz 11:847-855

Skupio R, Kubik B, Wolański K (2019) Spektrometryczne pomiary gamma rdzeni wiertniczych o niskiej aktywności. Nafta-Gaz 6:324-329

Środoń J, Drits VA, McCarty DK, Hsieh JCC (2001) Quantitative analysis of clay-bearing rocks from random preparations. Clays Clay Miner 49:6

Van der Graaf ER, Rigollet C, Maleka P, Jones DG (2007) Testing and assessment of large BGO detector for beach monitoring of radioactive particles. Nucl Instrum Methods Phys Res A 575:507-518

Vasiliev MA, Blum P, Chubarian G, Olsen R, Bennight C, Cobine T, Fackler D, Hastedt M, Houpt D, Mateo Z, Vasilieva YB (2011) A new natural gamma radiation measurement system for marine sediment and rock analysis. J Appl Geophys 75:455-463

Zagórska U, Gąsior I, Orzechowski M (2016) Ocena możliwośći budowy modelu geologiczno-geofizycznego dla utworów czerwonego spagowca z rejonu rowu Grodziska. Nafta-Gaz 11:901-909 